\title{
PROYECTOS Y REALIDADES: HIGIENE Y SALUD PÚBLICA EN LA CATALUÑA DE FINALES DEL SETECIENTOS
}

\author{
María del Carmen IRLES VICENTE \\ Universidad de Alicante
}

\begin{abstract}
Resumen
Los proyectos y realizaciones de los corregidores y alcaldes mayores que sirvieron en Cataluña en las últimas décadas del Setecientos constituyen el objeto del presente trabajo, que se centra en el análisis de dos cuestiones fundamentales: el saneamiento de las aguas en sus diferentes variantes (conducciones de agua potable, establecimiento de lavaderos públicos, alcantarillado), así como la mejora y ampliación de la red de carreteras, medida esta última con la cual se buscaba facilitar el abastecimiento urbano.
\end{abstract}

\begin{abstract}
The objects of the present work are the projects and accomplishments of the «corregidores» and «alcaldes mayores» who served in Catalonia in the last decades of the XVIII Century. And it is focused on the analysis of two fundamental problems: the reparation of the waters in their different ways (supply of drinking water, public washers establishment, sewer), as well as the improvement and amplification of the infrastructure, this last measure was the one with which it was sought to facilitate the urban supply.
\end{abstract}

El decreto de 29 de marzo de 1783, que reformaba la carrera corregimental, disponía en uno de sus artículos -el sexto- que antes de abandonar su destino tanto corregidores como alcaldes mayores habrían de realizar un informe sobre las medidas puestas en práctica en el distrito durante el periodo de ejercicio, así como destacar cuáles eran las necesidades básicas de la población y, consiguientemente, los proyectos que debería abordar con mayor celeridad su sustituto:

«le habrán de entregar una relacion jurada y firmada, en que expresen con distincion las obras públicas de calzadas, puentes, caminos, empedrados, plantíos ú otras que hubieren hecho, concluido ó comenzado en su tiempo, y el estado en que se hallaren las demas que fueren necesarias ó convenientes, segun su mayor necesidad ó utilidad, y los medios de promoverlas; el estado de agricultura, grangería, industria, artes, comercio y aplicacion 
del vecindario; los estorbos ó causas del atraso, decadencia ó perjuicio que padezcan, y los recursos y remedios que pueda haber»'.

En esos informes, cuya extensión y exhaustividad en el tratamiento de los temas variaba en función del interés con que el letrado de turno afrontaba su redacción, se pasaba revista al contingente poblacional existente, estado de la agricultura, desarrollo de la industria y el comercio, etc. Ha sido esta rica fuente de información, en concreto los primeros informes practicados por los titulares de las varas catalanas a raíz de la promulgación del referido decreto de 29 de marzo, la utilizada para la realización del presente trabajo, aunque limitada a un aspecto concreto: las medidas adoptadas, y proyectadas, para mejorar las condiciones de vida de la población catalana en las postrimerías del Siglo de las Luces.

Para efectuar un retrato, lo más fidedigno posible, de la situación en que se movían los catalanes del último cuarto del Setecientos prestaremos especial atención tanto a las múltiples carencias denunciadas por las autoridades, a los proyectos diseñados para eliminar esos inconvenientes, como a las realizaciones puestas en práctica. Para ello centraremos nuestro estudio en dos cuestiones fundamentales, el saneamiento de las aguas en sus diferentes variantes (conducción del agua potable, construcción de lavaderos públicos, canalización subterránea de las aguas fecales), así como la mejora y ampliación de la red de carreteras, medida esta última con la cual se buscaba facilitar el abastecimiento de ciudades y villas. También extenderemos nuestro análisis al estado sanitario de la población y a otra de las prácticas adoptadas para mejorar su calidad de vida: la plantación de árboles para su recreo. Como puede observarse, temas todos ellos muy en consonancia con el programa del despotismo ilustrado ${ }^{2}$.

\section{LASTRES Y AVANCES EN LA SALUBRIDAD PÚBLICA CATALANA}

La década de los ochenta comenzó con serios problemas sanitarios para la población catalana ${ }^{3}$. En 1781 y 1783 la villa de Agramunt sufrió «dos epidemias de calenturas pútridas malignas ${ }^{4}$, que pudieron ser cortadas gracias a la celeridad con que acometió su control el alcalde mayor Vicente Rovira y Martí, así como a la intervención de los doctores José Vidal, catedrático de Medicina de la universidad de Cervera, en el primer caso, y José Masdevall, inspector general de Medicina y médico honorario de Cámara de S.M., en la epidemia del año $1783^{5}$.

1. Novísima Recopilación de las Leyes de España, libro VII, título XI, ley 73.

2. REGUERA RODRÍGUEZ, A.T., Territorio ordenado, territorio dominado. Espacios, politicas y conflictos en la España de la Ilustración, León, 1993; LÓPEZ GÓMEZ, A., «Madrid en la época de Carlos III. Reformas urbanas y construcciones nuevas», Boletín de la Real Academia de la Historia, CLXXXV (sept.-dic. 1988), pp. 447-490.

3. PÉREZ MOREDA, V., Las crisis de mortalidad en la España interior. Siglos XVI-XIX, Madrid, 1980.

4. A.G.S. Gracia y Justicia. Leg. 825. Informe del alcalde mayor Vicente Rovira y Martí. Agramunt, 25 de febrero de 1784 .

5. MASDEVALL, J., Relación de las epidemias de calenturas pútridas y malignas, que en estos últimos años se han padecido en el Principado de Cataluña; y principalmente de la que se descubrió el pasado año de 1783 en la ciudad de Lérida, Llano de Urgel y otros muchos Corregimientos y Partidos... Imp. Real. 1786. 
Agramunt no fue la única población catalana en experimentar semejantes males, también en Igualada se prodigaron este mismo año muchas enfermedades y numerosos decesos ${ }^{6}$.

Además de las referidas epidemias, un tema que preocupó sobremanera al titular de la vara agramuntesa fue el de las muertes ocurridas a cinco vecinos de la población, que fallecieron de tisis. La razón de la expansión de la enfermedad la atribuía Rovira al poco cuidado que se ponía en recoger y quemar la ropa de los afectados tras su fallecimiento, así como a la tardanza con que los médicos ponían en conocimiento de las autoridades la existencia de dicho mal '. La solución, según el letrado, podría radicar en que los facultativos:

«dieran cuenta a la justicia el mismo día que advirtieran incurable la enfermedad, y declararan al paciente por ético o tísico consumado, y que en el propio día, o el más inmediato, acompañado el alcalde mayor del escribano de ayuntamiento, pasara a casa del enfermo y tomara riguroso inventario de todo lo existente en el cuarto y habitación de aquél, para quemarlo después de difunto, como se hace en la ciudad de Valencia, sin dejar puertas y ventanas y demás contaminado» ${ }^{8}$.

Si los fallecimientos humanos inquietaban a Vicente Rovira, también las repetidas muertes ocurridas en Balaguer a los ganados que iban a pacer en la partida del Gerp, y que mermaron sensiblemente el número de cabezas, despertaron el interés del alcalde mayor, quien hubo de tomar medidas para evitarlo. Aunque en un primer momento se pensó que dichas muertes provenían de alguna infección en la cabaña, tras numerosas tentativas y sahumerios para purificarla, sin obtener resultado positivo alguno, se optó por trasladar los ganados a otra zona mejor aireada donde los animales pudieran alimentarse sin temor a sucumbir como consecuencia de las malas condiciones ambientales, encontrando de esta manera la solución al problema".

$\mathrm{Si}$ la vigilancia y control de las enfermedades fue una de las tareas a las que debieron dedicarse corregidores y alcaldes mayores, más importante resultó la prevención de las mismas, así como las medidas adoptadas para evitar accidentes a la población; para ello revistieron especial interés las actuaciones emprendidas de cara al control del agua en sus diferentes vertientes: encauzamiento de ríos, canalización del consumo urbano, construcción de lavaderos, ampliación de la red de desagües, etc.

Entre los proyectos que según Mariano Berga y Felip urgía acometer en Granollers figuraba la reducción y enderezamiento del álveo del río Congost. La amplitud que con el paso del tiempo había adquirido el cauce tenía como consecuencia directa el acercamiento de las aguas a la villa, con el consiguiente peligro de desbordamiento en caso de crecidas, como de hecho se había experimentado ya en algunos huertos

6. A.G.S. Gracia y Justicia. Leg. 825. Informe de Buenaventura Claris y Postius. Igualada, 20 de marzo de 1784 .

7. Según apuntaba el alcalde mayor, «los médicos han aguardado siempre a darne cuenta después de difuntos».

8. A.G.S. Gracia y Justicia. Leg. 825. Informe del alcalde mayor Vicente Rovira y Martí. Agramunt, 25 de febrero de 1784.

9. A.G.S. Gracia y Justicia. Leg. 825. Informe de Antonio Quer y Villaró. Balaguer, 21 de diciembre de 1783. 
contiguos ${ }^{10}$. Para erradicar definitivamente este mal, sin tener que efectuar grandes desembolsos, el titular de la vara proponía recurrir a los vecinos de Granollers, así como a los de los pueblos de la Garriga, Llarona, Carro de Vall, Canovellas y Palou, y muy especialmente a quienes tuviesen tierras confinantes con el río, para

«formar, de acuerdo y bajo una misma regla y nivel, los correspondientes reparos, vulgarmente llamados acá rebugadas, plantando y formando en el intermedio de éstas su correspondiente arboleda, teniendo el debido cuidado de quitar las piedras grandes del curso de sus aguas y arando éste en el caso de engolfarse la arena en el mismo, para tener aquélla más libres sus corrientes»".

En el caso anterior hablábamos de proyecto, trataremos a continuación de realizaciones concretas. El alcalde mayor de Balaguer, Antonio Quer y Villaró, dedicó buena parte del tiempo que pasó al frente de la vara a mejorar la infraestructura hídrica de la población.

Poco después de llegar a la ciudad, y tomar posesión del empleo, Antonio Quer comprobó que el río Segre se había aproximado peligrosamente a la principal acequia con que contaba Balaguer -la ubicada en la partida de la Plana de Gerp-, de ahí que para evitar que se produjesen estragos en alguna de sus avenidas procedió a construir un nuevo tramo, alejándose en cuanto pudo del cauce del río. La enjundia de la obra queda patente a tenor de su coste, que alcanzó las 1.700 libras catalanas. No fueron éstas las únicas remodelaciones que se acometieron en la referida acequia.

Por defecto de construcción, la represa de la enunciada conducción se hallaba demasiado alta, razón por la cual en las avenidas del Segre entraba tanta agua en la misma que, por más que estuviesen abiertas todas sus compuertas y desaguaderos, causaba terribles daños al común de vecinos. Para subsanar definitivamente los contratiempos provocados por ese motivo, el titular de la vara mandó que en la entrada de la acequia se construyera un muro que contuviese «el impetu de las aguas por medio de unos ojos que se le dejaron»" ${ }^{12}$, los cuales únicamente permitían el paso del agua necesaria para el funcionamiento de los molinos de la ciudad, así como el riego de su huerta.

De la efectividad de las obras emprendidas da buena cuenta el hecho de que un solo hombre era suficiente para abrir y cerrar las compuertas; si a esto añadimos el escaso montante de aquéllas, cifrado en 598 lbs., nos percataremos de la puntualidad con que el letrado había supervisado su realización.

Interesado por cuanto supusiera mejorar el día a día de los habitantes de Balaguer, así como la estética de la población, Quer y Villaró ordenó reparar las murallas $\ll y$ que se hermoseasen sus puertas lo mejor que permitiese lo tosco de las obras, añadiendo en la entrada de la que llaman de Gerp unos parapetos que fuesen preser-

10. Según manifestaba el alcalde mayor en su informe, la necesidad de reformar el cauce del río venía impuesta «por ser muy vasto y espacioso el que ahora tiene, haberse notablemente acercado sus aguas a este pueblo, y amenazarle éstas no poca ruina, como la ha causado en sus huertos».

11. A.G.S. Gracia y Justicia. Leg. 825. Informe de Mariano Berga y Felip. Granollers, 8 de enero de 1784.

12. A.G.S. Gracia y Justicia. Leg. 825. Informe de Antonio Quer y Villaró. Balaguer, 21 de diciembre de 1783. 
vativos de las desgracias en lo sucesivo, que se habian experimentado asi por la pared del río como por la de la acequia que entra en aquella parte». También ordenó cubrir con bóveda un buen tramo de la acequia ubicada en las inmediaciones de las escuelas pías para evitar de esta forma que siguieran sucediéndose accidentes como los que habían ocasionado la muerte de varios niños, quienes habían perecido ahogaldos. Con la módica cantidad de 630 lbs. lograron llevarse a efecto las mencionadas obras.

La contención de las aguas que discurrían incontroladas fue también objeto de especial atención por parte de otros corregidores y alcaldes mayores y, entre ellos, por Mariano Berga y Felip. Para solventar este inconveniente Berga acometió la construcción de una acequia en Granollers, de 771 varas de largo por 15 cuartas de ancho, destinada a recoger aquellas aguas que, cuando se producían lluvias, bajaban de los montes y sierras de los alrededores y se dirigían a la población inundando «todas o las más de sus casas», las cuales, por estar mayoritariamente erigidas de tapia, quedaban «notablemente expuestas a derribarse y a quedar entre las ruinas las vidas de sus habitantes» ${ }^{13}$.

Un problema similar al comentado se encontró Nicolás María Esteban en Montblanch. Por su ubicación, al pie de la montaña, en la referida villa confluían las aguas caídas en sus vertientes, las cuales acababan canalizándose en sendos barrancos que se juntaban a unos 600 pasos de la población para penetrar posteriormente en la misma a través de la Puerta de la Sierra y, 300 pasos más adelante, introducirse en un conducto subterráneo que la cruzaba casi en su totalidad. Alrededor de 100 pasos antes de abandonar el núcleo urbano las aguas del barranco afloraban de nuevo, para acabar saliendo por otra de las puertas e incorporarse acto seguido al río Francolí.

$\mathrm{Ni}$ qué decir tiene que cuando sobrevenían tormentas intensas, las aguas de los barrancos, debido a su rapidez y abundancia, arrastraban grandes cantidades de arena, cantos y maleza que llegaban a dificultar, e incluso impedir, su curso por el conducto subterráneo, reventando, en ocasiones, en el interior de algunas de las viviendas que hallaban a su paso; en casos extremos los materiales acumulados bloqueaban totalmente el trayecto interno del agua provocando inundaciones en «los almacenes y bodegas de la mayor parte de las casas, hasta verse en las entradas y cuartos de ellas más de una vara de agua» ${ }^{14}$.

La relativa frecuencia con que se prodigaban estas circunstancias en Montblanch hacía que sus moradores mirasen con cierta preocupación al cielo cada vez que empezaba a llover.

Un episodio de especial angustia y virulencia se vivió en la población en la noche del 2 de abril de 1771 cuando, después de una hora diluviando, «así por sobresalirse el agua por encima de dicho conducto, como por reventarse éste en distintas casas», los vecinos vieron cómo se inundaba la villa, al tiempo que diferentes viviendas quedaban totalmente arruinadas.

13. A.G.S. Gracia y Jusicia. Leg. 825. Informe de Mariano Berga y Felip. Granollers, 8 de enero de 1784.

14. A.G.S. Gracia y Justicia. Leg. 825. Informe de Nicolás Maria Esteban. Montblanch. 15 de noviembre de 1783 . 
Fue tal la magnitud del siniestro que el arzobispo de Tarragona, Juan Laurio Lancis, que por esas fechas se hallaba visitando la población, mandó al párroco que saliese por las calles con el Santísimo Sacramento en las manos para implorar la protección del Altísimo. El cese de las lluvias, unido a las acertadas providencias adoptadas por las autoridades políticas locales, con la colaboración de «muchos hombres», consiguieron paliar en parte los daños ocasionados por las inundaciones.

Visto el problema que de manera recurrente se presentaba a los vecinos de Montblanch, no es de extrañar que el alcalde mayor Esteban considerase que una de las obras que con mayor urgencia cabía acometer era el desvío del cauce de los referidos barrancos. Junto al mencionado proyecto, en los papeles que Nicolás María Esteban dejó a su sucesor para que tuviera constancia de cuáles eran las necesidades más perentorias figuraba otro: la canalización del agua de la fuente.

El conducto que transportaba el agua para el abastecimiento de la población tenía un serio inconveniente: desde su origen hasta las proximidades de la villa discurría al descubierto, lo que ocasionaba que:

«siempre que llueve viene excesivamente turbia y asquerosa el agua, y en este estado permanece algunos dias».

Este enturbiamiento se debía en buena medida a la incorporación de aguas procedentes de los campos vecinos y de los barrancos que descendían del monte llamado popularmente de la Pascuala. Sin embargo, lo que más contribuía a deteriorar el agua no era ese aporte extra procedente de las lluvias, sino las inmundicias que introducían los animales que vagaban sueltos por los alrededores, los cuales,

«no teniendo ningún impedimento, se introducen en su cauce para beber, ensuciando el agua de manera que conocidamente ciegan los excrementos los caños de las fuentes, y se ven salir por ellos los de toda especie de animales, haciéndose anualmente en el engibre contiguo a los mismos caños un depósito de cieno tan putrefacto, por las referidas y otras inmundicias, hasta de sabandijas y animales muertos, que llegan a corromper el agua» ${ }^{15}$.

La alteración del sabor del agua como consecuencia de la incorporación de excrementos y cadáveres de animales era especialmente notable en el verano, por efecto de las altas temperaturas, percibiéndose al beber «el malísimo gusto de la putrefacción». Otro contratiempo debían soportar los vecinos de Montblanch en la estación veraniega: tomar el agua caliente.

Para subsanar los enunciados problemas, y poder beber «el agua clara, limpia, fresca y saludable», los regidores de Montblanch solicitaron en febrero de $1779 \mathrm{el}$ permiso del Consejo para proceder a las necesarias obras, costeándolas del sobrante de propios. Los informes del alcalde mayor de la población y del intendente de Cataluña corroboraron las sobradas ventajas que reportaría a la villa tanto el desvío del trayecto de los barrancos como el cubrimiento de la conducción de agua para la fuente, pasándose acto seguido a justipreciar por expertos su coste.

\section{Ibidem.}


Una vez elaborados los mapas pertinentes, y fijados los capítulos o condiciones que debían cumplir quienes fueran a acometer su realización ${ }^{16}$, las obras fueron sacadas a pública subasta. En el caso de la canalización de los barrancos su coste fue evaluado en 4.000 libras, siendo finalmente rematadas en 3.376 a favor de Buenaventura Roses y Juan Serra, vecinos del lugar de Sarriá; en el caso del agua de la fuente se estimó que serían necesarias 2.600 lbs., si bien el mejor postor, los mismos Roses y Serra, se ofreció a realizarlas por 2.844; ambas construcciones llevaban agregados unos gastos de mantenimiento que se cifraban en 12 y $15 \mathrm{lbs}$. anuales, respectivamente.

Como ya apuntamos, los regidores pensaban sufragar el coste de las obras de los sobrantes de propios y arbitrios, de ahí que solicitasen el correspondiente permiso; sin embargo, una orden del intendente, comunicada el 7 de enero de 1780, les hizo desistir de su propósito al mandarles expresamente:

«la suspensión, desde luego, de la aplicación de los caudales sobrantes de propios y arbitrios que hubiese existentes en arcas, aunque estuviesen destinados por órdenes del Consejo, o del mismo intendente, para luición de censales, para pagos de pensiones atrasadas, o para obras, suspendiendo las comenzadas, donde no se pudiese seguir grave perjuicio, hasta nueva orden».

La negativa del barón de Lalinde ${ }^{17}$, intendente de Cataluña por esas fechas, a emplear los bienes de propios en la ejecución de las obras reseñadas llevó al alcalde mayor a proponer el recurso a otro sistema. Según indicó Nicolás María Esteban, la villa disponía desde tiempo inmemorial de un terreno contiguo a los muros, ubicado entre la puerta de la Sierra y la de San Francisco, de unos 700 pasos de largo, por 15 ó 20 de ancho, que era arrendado anualmente y redituaba, unos años con otros, alrededor de 30 libras. Para conseguir fondos con los que costear las construcciones, Esteban proponía dividir el solar en trozos de 30 ó 40 palmos cada uno, que se destinarían para patios de casas, corrales, huertos o fábricas de aguardiente, y se venderían, «según la anticuada costumbre que hay en la enajenación de semejantes propios, por un correspondiente capital que se da, y llama de entrada, de 40, 50 o más libras, y con la imposición de un annuo censo perpetuo, con la reserva del dominio directo, luismo y fadiga, y con la obligación de mantener los muros».

Con el recurso al procedimiento recomendado por el alcalde mayor se conseguiría un capital con que sufragar las obras, al tiempo que la villa seguiría percibiendo anualmente una cantidad similar a la que había cobrado hasta ese momento.

Un proyecto similar al que proponía Nicolás María Esteban para Montblanch fue defendido por Mariano Berga para Granollers. Pese a que el agua de la fuente con

16. Quienes consiguieron la concesión de la primera de las obras se obligaron «a construir la correspondiente calzada en el lugar donde se unen los dos barrancos, comenzando de la misma calzada un conducto subterráneo muy firme y capaz para desaguar por él las aguas del rio Francoli, habiendo de construir a proporcionadas distancias respiraderos o minas para la mejor permanencia y limpieza»; mientras que los postores que se quedaron con la segunda debían realizar «el conducto que desde su origen llegase hasta el mismo engibre y caños de la plaza, todo cubierto, y a ciertas partes de losas y canales de piedra labradas.

17. Manuel Antonio Terán y Bustamante, barón de Lalinde, ocupó la intendencia catalana entre 1776 y 1789. Sobre su trayectoria administrativa vid. ABBAD, F. y OZANAM, D., Les intendants espagnols du XVIII siècle, Madrid, 1992, p. 175. 
que se abastecía esta villa era buena y abundante en origen, la inexistencia de una cañería que la aislase del exterior provocaba serios contratiempos en el verano, como la alta temperatura a la que llegaba a sus consumidores o la falta que frecuentemente experimentaban del líquido elemento, «ya porque se cuela y desvía del actual conducto, o bien porque se desgaja dentro [de] éste alguna porción de tierra». Las frecuentes reparaciones que debían realizarse para solventar este último problema ocasionaban cuantiosos gastos al municipio, de ahí que el alcalde mayor abogase por cerrar la conducción del agua construyendo una cañería de cal y canto ${ }^{18}$.

Mientras en los casos anteriores el problema venía originado por discurrir al aire libre las aguas que abastecían las poblaciones de Montblanch y Granollers, otras veces era la ausencia del líquido elemento la que quitaba el sueño al alcalde mayor.

La tradicional falta de agua potable que experimentaban los habitantes de Balaguer se debía tanto a la inexistencia de «una fuente abundante y perenne», como a las pésimas condiciones en que bajaba el caudal del Segre durante buena parte del año ${ }^{19}$, de ahí que el titular de la vara se plantease la construcción de una fuente «dulce y sana».

Dos sistemas distintos ideó Antonio Quer y Villaró para abastecer del líquido elemento a la población; el primero consistía en comprar el agua de la fuente de Macip, situada a una legua de Balaguer, y conducirla, «por una subterránea mina», hasta la ciudad. Sin embargo, ésta parecía una empresa de mucho trabajo y coste, por lo que el letrado se inclinaba por acometer el segundo, consistente en:

"hacer unos pozos inmediatos a la acequia principal, un poco antes de su entrada en la puerta que llaman de Gerp, hacer filtrar de continuo en ellos una buena porción de la agua que corre por aquélla, y después construir unas bombas que, mediante una máquina que de noche y día harían trabajar las corrientes de la misma acequia, elevasen el agua necesaria a un proporcionado edificio que sirviese de depósito, para distribuirla por los caños diferentes a las fuentes que se quisiesen construir en la ciudad" ${ }^{20}$.

Para llevar a cabo el proyecto anterior, que según Antonio Quer podría costar entre seis y siete mil ducados, éste recomendaba consultar a un hábil fontanero que tenían los capuchinos en su convento de Cervera.

Desconocemos cuál fue el sistema finalmente adoptado en Balaguer, careciendo también de datos sobre las medidas puestas en práctica en Tárrega, donde Mariano Berga y Felip aludía a la necesidad de instalar una fuente permanente «de agua buena para beber y limpiar la ropa blanca», la cual podría ser costeada del sobrante de sus propios y arbitrios. Algunos años atrás ya se habían practicado diligencias con el fin de localizar agua de calidad para el enunciado fin; dichas gestiones habían dado su fruto al encontrarla «muy buena, saludable y abundante» en la partida del Riambau, «sólo un cuartito de legua distante de este dicho pueblo», por lo que se pensaba que no sería muy costosa su conducción hasta la villa.

18. Mariano Berga recomendaba la construcción de treinta o cuarenta varas anuales de «una buena y permanente cañería de cal y cantor, a costear del sobrante de propios y arbitrios. A.C.S. Gracia y Justicia. Leg. 825. Informe de Mariano Berga y Felip. Granollers, 8 de enero de 1784.

19. Según Antonio Quer, las aguas del Segre bajaban «por los nueve meses del año, lo que menos (....) las más sucias y cenagosas»».

20. A.G.S. Gracict y Justicia. Leg. 825. Informe de Antonio Quer y Villaró. Balaguer, 21 de diciembre de 1783. 
La principal preocupación de los letrados a los que venimos refiriéndonos últimamente era cómo abastecer de agua potable las poblaciones en donde ejercían su jurisdicción, preocupación que solía ir acompañada, las más de las veces, de cómo evitar que las aguas residuales acabaran afectando a la salud pública. Puesta la mirada en estas cuestiones, el alcalde mayor de Agramunt abogaba por la construcción de un lavadero público «donde pueda lavarse la ropa en los días que viene turbia la agua del río, y cuando en tiempo de verano queda estancada sin tener la menor corriente, en cuyo caso se corrompe y se comunica la putrefacción a la ropa, y con facilidad transciende a los cuerpos y causa enfermedades» ${ }^{2 i}$.

Para evitar los referidos males Vicente Rovira y Martí, titular de la vara agramuntesa entre 1779 y 1784, consideraba imprescindible, asimismo, limpiar las cloacas existentes en algunas calles, así como continuar el trazado de la red general de alcantarillado «por las que no le hay, por donde puedan discurrir las aguas y suciedades que en el día se echan a la calle, porque la continuación de unas y otras corrompen el aire y con facilidad se introduce en los cuerpos la putrefacción y causa las enfermedades epidémicas» ${ }^{22}$.

Sobre la conveniencia de ampliar la red de alcantarillado, y el consiguiente empedrado de las calles, había sido informada ya la Junta de Sanidad de la ciudad de Barcelona en 1781 y solicitado presupuesto al arquitecto Jaime Tarragó, «el de mayor habilidad que se conocía por estos contornos», quien cifró el coste en 1.700 libras catalanas.

La preocupación del titular de la vara agramuntesa no acababa en la realización del enunciado proyecto; de hecho, para prevenir el deterioro de la construcción, caso que ésta se llevase finalmente a efecto, Vicente Rovira sugería adoptar una serie de medidas como la imposición de multas a aquellos vecinos que tirasen agua o cualquier otra cosa a la calle, «así de día como de noche»; que los carros entrasen y saliesen de la villa por la puerta más próxima a la casa de sus dueños; y que cuando a causa del repetido tránsito se descompusiera parte del empedrado se reparase por cuenta de los propietarios, sirviendo de ayuda de costa las cantidades ingresadas en concepto de multas.

Como en Agramunt, también en Tárrega la construcción de albañares y el empedrado de calles figuraban entre las obras públicas que más urgía acometer, según Mariano Berga.

Uno de los principales proyectos a realizar en la villa era la instalación de albañares en todas las calles para el desagüe de las aguas residuales generadas en las viviendas, las cuales, por carecer de pozo o patio interior, acababan vertiéndolas a la

21. Sobre lá doctrina miasmática, imperante entre los científicos de la época, según la cual el estancamiento y corrupción de las aguas eran las causantes de numerosas enfermedades vid. BARONA VILAR, J.L., y MICO NAVARRO, J.A., «Cavanilles y los problemas sanitarios de la Ilustración», Saitabi XLII (1992), pp. 117-133, esp. 119 y ss.; y «La higiene y sanidad de las comarcas castellonenses en el siglo XVIII, a través de las Observaciones... de Cavanilles», Estudis Castellonencs $n^{\circ} 5$ (1992-93), pp. 467-482. CARRERAS PANCHÓN, A., Miasmas y retrovirus, Barcelona, 1991. CIPOLLA, C.M., Contra un enemigo mortal e invisible, Barcelona, 1993.

22. A.G.S. Gracia y Justicia. Leg. 825. Informe de Vicente Rovira y Martí. Agramunt, 25 de febrero de 1784. 
vía pública. Esta práctica cotidiana, además de generar suciedad y malos olores, era notablemente perjudicial para la salud pública, de ahí que tendiera a ser erradicada ${ }^{23}$.

Para que la operatividad de la red de alcantarillado fuese mayor Berga y Felip recomendaba el desvío del agua de una acequia próxima a la población:

«con cuyos albañares quedarian estos males remediados, mayormente pudiéndose conducir a los mismos albañares, con mucha facilidad, la agua de una acequia que pasa por la parte superior del pueblo, mediante la que estarian de continuo limpios y corrientes ${ }^{24}$.

Otras medidas propuestas por el alcalde mayor, esta vez para mejorar el aspecto general de Tárrega, así como conseguir que la villa quedase libre de lodo en tiempo de lluvias, consistían en blanquear con cal el exterior de todas las viviendas y concluir el empedrado de calles, «conforme se practicó años atrás con las más de ellas» ${ }^{25}$.

La misma tónica de perfeccionar la salubridad pública mediante la construcción de alcantarillados, observada ya en otras poblaciones catalanas, se prodigó asimismo en Balaguer. Preocupado enormemente por las condiciones en que se hallaba la plazuela de la Botera, donde permanecía abierta una antigua cloaca que «no sólo hacía intransitable su calle, sino que por los veranos, y aun en los inviernos, echaba un mal olor que apestaba y enfermaba» a sus habitadores, Antonio Quer propuso al ayuntamiento acometer las obras más imprescindibles, reducidas a cerrar la conducción de las aguas fecales y empedrar toda la plaza. De la efectividad de las medidas adoptadas da buena cuenta la transformación sufrida por el entorno; si nos atenemos a las palabras del alcalde mayor, se había logrado dejar «una plaza que antes era un verdadero muladar, la más bella y limpia entre las iguales» ${ }^{26}$.

Como la plazuela de la Botera, también la calle de Avall, la de más tránsito y concurso de la ciudad, se hallaba en una situación lamentable; el origen de su pésimo estado radicaba en los vertidos practicados por sus vecinos, y que la convertían en «la más sucia de todas, de manera que se hacía imposible transitar por ella a pie, por hallarse del todo encharcada de aguas sucias y lodos proveniendo de las que vertian las casas que corren por la misma». La solución adoptada en este caso fue la misma que se aplicó en la mencionada plaza: abrir unas alcantarillas y empedrar la calle.

Entre los logros de Antonio Quer figuraba, asimismo, el blanqueo de las fachadas de las casas que conformaban la principal plaza de Balaguer, cuyo aspecto anterior criticaba el letrado en los siguientes términos:

«teniendo esta ciudad una espaciosa plaza, tal que por su capacidad y buena situación no tiene el Principado otra que la iguale, era la cosa más ridícula que las casas que la rodean presentasen casi todas su frente y aspecto el más desordenado y ridículo, no sólo por la desigualdad y mal orden de las dichas, sino por su negrura y sucio».

23. La previsión con que actuaban los alcaldes mayores catalanes en este terreno se pone especialmente de manifiesto si lo comparamos con la situación imperante en la capital francesa no sólo por esas mismas fechas, sino incluso muy entrado el siglo siguiente. GUERRAND, R.-H., Las letrinas. Historia de la higiene urbana, Valencia, 1988.

24. A.G.S. Gracia y Justicia. Leg. 825. Informe de Mariano Berga y Felip. Tárrega, 2 de junio de 1784

25. Según Berga y Felip dichas obras deberían costearlas los propios vecinos de la población.

26. A.G.S. Gracia y Justicia. Leg. 825. Informe de Antonio Quer y Villaró. Balaguer, 21 de diciembre de 1783. 
Quer y Villaró trató de enmendar el estado de abandono de las viviendas, y la desidia de quienes le habían precedido en el empleo, persuadiendo y obligando a sus propietarios a dar «un baño y blanqueo en lo exterior de todas las afrontaciones con dicha plaza»; a finales de 1783 sólo nueve de esos inmuebles mantenían su deteriorada apariencia, confiando el alcalde mayor en que pronto lucirían mejor aspecto.

Pese a las numerosas tareas acometidas, todavía se echaba en falta la realización de otras muchas, como la construcción de una completa red de alcantarillado que comprendiese todas las calles de la ciudad; de esa forma se conseguiría un doble objetivo: que éstas permaneciesen limpias y que el aire quedase libre de malos olores, lo que repercutiría en la mejora de las condiciones de vida de sus habitantes. De hecho, la experiencia acumulada por Quer y Villaró en los cerca de cuatro años que llevaba al frente de la vara le llevaron a proclamar que «la mayor parte de las enfermedades que se experimentan repetidamente entre estos vecinos nacen de la infección del aire, que no puede dejar de suceder habiendo tanta ediondez en las tales calles».

\section{UN DÉFICIT A SUBSANAR: LA AMPLIACIÓN DE LA RED DE CARRETERAS}

Comentábamos al comienzo de este trabajo que iban a ser dos los puntos de atención prioritarios: agua y carreteras. Ya nos hemos ocupado con amplitud del primero de dichos temas, así como del empedrado de calles dentro de las poblaciones, aspecto éste que solía abordarse en conexión con la creación o ampliación de la red de alcantarillado; resta ocuparnos de las carencias que los alcaldes mayores catalanes detectaron en la red viaria del Principado, así como los proyectos elaborados para paliarlas y, de manera indirecta, mejorar el abasto de la población.

El alcalde mayor de Montblanch, Nicolás María Esteban, reconoció que durante el tiempo que había permanecido al frente del cargo únicamente se había concluido el empedrado de un camino, el que iba desde una de las puertas de la villa, la llamada «de la Sierra», hasta el que conducía al convento de monjas de Santa Clara. Pese a sus reducidas dimensiones, el nuevo empedrado, que tenía unas medidas de 25 palmos de ancho por 160 de largo, resultaba suficiente para impedir los fosos, bastante profundos por cierto, que se formaban con las avenidas de los barrancos de San Juan y las Comas, los cuales pasaban juntos por la referida puerta, y cuyas concavidades dificultaban el tránsito de las caballerías ${ }^{27}$.

La mejora de las vías de comunicación fue una tarea en la que invirtieron buena parte de su tiempo la mayoría de los letrados que se ocuparon de las varas catalanas. Durante su estancia en Granollers Mariano Berga se dedicó sobre todo al camino real que unía la ciudad de Barcelona con la de Vich, en el cual procedió a suavizar los desniveles existentes y a recomponer los socavones provocados por las aguas que, en época de lluvias, bajaban de las sierras circundantes. También se ocupó de empedrar diferentes calles, como las de Corro y Barcelona, que se hallaban intransitables las más de las veces por el motivo ya expuesto ${ }^{28}$.

27. A.G.S. Gracia y Justicia. Leg. 825. Informe de Nicolás María Esteban. Montblanch, 15 de noviembre de 1783.

28. A.G.S. Gracia y Justicia. Leg. 825. Informe de Mariano Berga. Granollers, 8 de enero de 1784. 
Además de reparar las murallas y puertas de Balaguer, según comentamos más arriba, Antonio Quer y Villaró procedió a ensanchar y enderezar el trayecto de la carretera que desde la llamada puerta de Lérida se dirigía a esta población, «con la capacidad de poder pasar cómodamente tres carros de frente en lugar que antes, con trabajo, pasaba uno». Para completar las mejoras del vial mandó plantar dos hileras de árboles en sus márgenes, conformando con ellos un agradable paseo que no sólo servía de utilidad a los viajantes, sino que facilitaba el recreo de los propios vecinos de Balaguer.

Aunque con las medidas emprendidas por Quer se había logrado mejorar sensiblemente la circulación de los viajeros por la carretera que comunicaba la villa de Balaguer con Lérida, todavía se echaba en falta la intervención en aspectos concretos; de ahí que el mencionado alcalde mayor recomendase a su sucesor continuar con las obras de ensanche y acondicionamiento en todo el tramo incluido dentro del término ${ }^{29}$.

En la misma línea de los letrados anteriores, informaba en marzo de 1786 el andaluz Pedro Manuel de Lazcano sobre las diferentes obras públicas acometidas en la villa de Berga desde septiembre del año 1782, momento en que se había hecho cargo de la vara. Durante los casi cuatro años que separaban ambas fechas Lazcano había emprendido la construcción de dos paredes de piedra en el camino real que desde dicha población se dirigía a las de Cardona y Solsona, «en dos sitios llamados los abeuradors», y donde sendos arroyos habían provocado grandes «quebradas y excavaciones», dejando prácticamente intransitable el referido camino.

Las labores llevadas a término en la zona de los abeuradors, o abrevaderos, no se limitaron a eliminar el desnivel del suelo, ya que también se instaló en dicha área una fuente con su correspondiente abrevador para los ganados, la cual resultó de gran utilidad tanto a los naturales como a los transeúntes, que carecían hasta ese momento «de dicho beneficio por hallarse aquélla en sitio oculto y como [a] unos cuarenta pasos del mismo camino» ${ }^{30}$.

Para completar las mejoras del lugar, también se plantaron algunos árboles que sirvieran de recreo a quienes hicieran un alto en el camino para descansar y beber las aguas de la nueva fuente. Con el mismo fin de facilitar la «recreación pública» se instalaron tres hileras de árboles extramuros de la villa, en el llamado Vall de l'Estudi.

Si las realizaciones se limitaban a los ejemplos reseñados, los proyectos iban mucho más lejos, estimándose preciso acometer obras importantes como la construcción de una carretera que comunicase Berga con la ciudad de Manresa, pues hasta la fecha todo el transporte de mercancías existente entre ambas poblaciones se hacía a lomo de caballerías. La urgente necesidad de crear dicho vial radicaba tanto en las escasas cosechas que se recogían en la zona, y que obligaban a traer los suministros de

29. Para lograr el ensanche de la carretera deberían derribarse las tapias que la flanqueaban por la parte del mediodía, y que eran las responsables del penoso estado en que se encontraba el vial durante buena parte del año, pues «sin esta operación nunca se logrará cómoda y sin que se encharquen en ella las aguas de todos tiempos, causa por que se halla ahora intransitable». A.G.S. Gracia y Justicia. Leg. 825. Informe de Antonio Quer. Balaguer, 21 de diciembre de 1783.

30. A.G.S. Gracia y Justicia. Leg. 825. Informe de Pedro Manuel de Lazcano. Berga, 26 de marzo de 1786. 
otros lugares, como al alto precio que se pagaba por éstos debido a las condiciones del transporte ${ }^{31}$ :

«como en este partido sean las cosechas cortas, tanto por lo montuoso del terreno, y su temperamento frío, como por lo muy poblado que se halla, se ha de conducir cuasi todo de fuera, y en particular el vino, de que no hay cosecha algunas.

$\mathrm{Ni}$ qué decir tiene que la puesta en práctica del enunciado proyecto requería grandes desembolsos, por lo que el alcalde mayor debió especificar de qué fondos habría de sufragarse. Entre los medios arbitrados figuraba la imposición de un gravamen sobre la venta del vino ${ }^{32}$, un repartimiento equitativo entre los vecinos de Berga, así como la participación de la ciudad de Manresa y demás pueblos que se vieran beneficiados por la construcción de la carretera, «como son aquéllos por donde ésta pasaría, los de sus inmediaciones y los más que componen este partido, que le lograrían igaal al de la villa de Berga».

Con la apertura de esta vía de comunicación no sólo se conseguiría un ahorro de alrededor de 120.000 reales en el transporte del vino, sino que también se lograría una reducción en el número de caballerías necesarias para los suministros ${ }^{3,3}$, con la consiguiente disminución del gasto a realizar en grano y paja para su alimentación. Además, se potenciaría el comercio en la zona ${ }^{34}$.

También entre las prioridades del alcalde mayor de Besalú, Santiago Núñez de Santamaría, figuraba la construcción de una carretera que permitiera mejorar las comunicaciones con las poblaciones vecinas. Para hacernos una idea de las carencias existentes nada más gráfico que reproducir sus propias palabras:

«No se ve a dos leguas en sus contomos rastro ni reliquias de obras públicas de calzadas, caminos formales empedrados, ni puentes, sino el de la entrada por la parte de Gerona, adonde con inmenso trabajo llega un carruaje, sube aligerado con grave fatiga a la villa, sin poder desde ella pasar más adelante transversal ni rectamente» ${ }^{35}$.

Situada en las inmediaciones de Olot, Figueras y Bañolas, villas que por su industria y fábricas de algodón y lana veían crecer día a día «su opulencia y vecindario», parecía bastante probable que de mejorarse las comunicaciones existentes entre estas poblaciones y la ciudad de Gerona podría producirse un desarrollo similar en la propia Besalú.

31. Para suministrar mercancías a la villa de Berga se empleaban unas «doscientas caballerias mayores». siendo Ia utilización de este medio de transporte la responsable de la subida que se venía advirtiendo en el precio de los productos.

32. Se aludía a gravar la venta de vino al por mayor con diez sueldos cada carga -el gravamen habitual era de cinco sueldos-, así como imponer un dinero por porrón en la venta al por menor.

33. Se estimaba que con la tercera parte de las existentes en ese momento sería suficiente.

34. Auguraba el alcalde mayor que, tanto en Berga como en sus alrededores, se instalarían almacenes de viveres «en los que se vendería con tanta conveniencia como en la ciudad de Barcelona, excusándose asi dichos pueblos, y la mayor parte de la Cerdaña, el hacer. como ahora hacen, su giro a dicha ciudad a sacurlos para proveer con ellos a los pueblos».

35. A.G.S. Gracia y Justicia. Leg. 825. Informe de Santiago Núñez de Santamaría. Besalú, 24 de diciembre de 1783 . 
El trazado propuesto por Núñez para la nueva carretera tenía su origen en Olot, de donde bajaba hasta Besalú; una vez en esta población, por su puente y el del lugar de Esponella, continuaba hasta Figueras y el puerto de Rosas. El proyecto se completaba con un brazo que desde el referido puente de Esponella comunicaba la zona, a través de Bañolas, con Gerona, la Bisbal y Torroella, para concluir en el puerto de lá Escala, lográndose de esta manera un nexo de unión entre la Montaña y la costa del Ampurdán ${ }^{36}$.

La privilegiada posición de Besalú, situada a mitad de camino entre dos villas florecientes como Olot y Figueras, la convertían en lugar ideal para el intercambio de las producciones de ambas comarcas, así como servir de «proporcionado almacén de los efectos iransportados de la parte de Gerona, Marina y Barcelona, y hacer desde aquí el comercio de la Montaña e interior de esta parte de provincia».

Además de servir de acicate para «adelantar aquí los plantíos, el comercio, avivar la industria, fomentar la agricultura y dar su todo a las artes en este terreno y villa», todavía podría reportar otra ventaja la mencionada carretera, esta vez para la Real Hacienda, habida cuenta del «menos coste que ocasionaria al Real Erario la madera que de calidad escogida, y en una considerabilísima abundancia, desciende de estas montañas al puerto de Rosas para la Marina de Su Majestad».

Reseñadas las innumerables cualidades del nuevo vial, sólo faltaba arbitrar de qué fondos sufragar los cuantiosos gastos que su construcción requería. El alcalde mayor de Besalú estimaba que todos los pueblos del corregimiento de Gerona deberían contribuir a su financiación, ya que su aprovechamiento iba a ser universal, si bien establecía una doble modalidad a la hora del reparto. Según Santiago Núñez, las villas grandes, y que contaban con bienes de propios, habrían de sufragar la mayor parte del gasto, mientras en el resto de poblaciones la cantidad que les fuera asignada sería repartida entre sus vecinos «a estilo de catastro».

Puesto que los pueblos englobados dentro del corregimiento de Gerona eran más de cuatrocientos, Núñez Santamaría consideró factible recaudar alrededor de las $36.000 \mathrm{lbs} .{ }^{37}$. No obstante, antes de proceder a la imposición de cualquier gravamen a las citadas poblaciones, el alcalde mayor de Besalú proponía que varios ingenieros revisaran el trazado de la carretera en cuestión para evaluar las obras a acometer y su posible coste, todo lo cual quedaría reflejado en una escritura.

Coincidiendo con la salida a pública subasta de las obras empezaría la recaudación de su montante; las cantidades recogidas se confiarían al mayordomo de propios de la ciudad de Gerona, quien daría a cada pueblo un recibo en el que figurase la cantidad entregada. Como garantes de la legalidad y limpieza del proceso figuraban el

36. Con la construcción de la nueva carretera se lograría mejorar sensiblemente las comunicaciones, consiguiéndose un notable ahorro de tiempo, ya que según las apreciaciones del alcalde mayor se podría realizar el trayecto de Olot a Rosas en unas doce horas, y de Esponella a Gerona en unas cuatro.

37. Especulando con la recaudación total que podría obtenerse indicaba Núñez Santamaría que ken más de cuatrocientos pueblos de comprensión total de este corregimiento de Gerona, a tres doblones de a ocho cada uno ya ascendería a más de treinta y seis mil libras o treinta y cinco mil ducados de vellón, a corta diferencia; y cargando a proporción de los caudales de propios apenas puede al mayor lugar, donde no los haya, tocar el repartimiento de un doblón de a ochos. 
corregidor de Gerona y el alcalde mayor de Besalú, quienes debían conservar en su poder dos libros separados en los que figurarían tanto las cantidades ingresadas como los pagos realizados.

Como hicieron otros muchos alcaldes mayores, entre las primeras tareas acometidas por Mariano Berga y Felip tras tomar posesión de la vara de Tárrega figuró la composición de caminos, siendo la que comunicaba Barcelona con Madrid una de las calzadas que fue objeto de especial atención. Pues bien, para reparar el tramo de este vial que atravesaba la villa de Tárrega, el letrado mandó «terraplenar, con copia de canto por dentro y grava o arena por encima, los muchos y peligrosos pantanos de que abundaba» ${ }^{38}$, Ios cuales tenían su origen en las copiosas y repetidas lluvias que se prodigaban a lo largo del invierno. La cantidad de agua caída dejaba buena parte del año el camino intransitable y, como consecuencia de ello, expuestos los viajantes a continuos riesgos y daños, como también a quedarse atascados los carruajes.

Durante los apenas tres meses que permaneció Berga y Felip en su destino tarreguense ordenó, asimismo, sacar de las entradas de la villa, y de todos sus arrabales, los montones de tierra, piedra y estiércol que impedían o dificultaban el tránsito, limpiando el pueblo «de tanto embarazo e inmundicia» como encontró a su llegada.

La rapidez con que fue promovido a la vara gerundense impidió a Mariano Berga tomar otras medidas para mejorar el estado de la población ${ }^{39}$, pero no ver sus necesidades, que dejó detalladas a su sucesor para que éste procediera a solventarlas, según hemos tenido ocasión de comentar.

Buenaventura Claris y Postius, alcalde mayor de Igualada en 1784, afirmó que durante los quince meses que permaneció en dicho destino las únicas obras públicas puestas en ejecución fueron el empedrado de un camino que comunicaba la calle de la Soledad, en los Arrabales de dicha población de Igualada, con las tenerías y tinturías existentes a orillas del Noya ${ }^{40)}$, así como «algunos remiendos de corta duración hechos en la carretera que va de Madrid a Barcelona y pasa por los términos de Odena, Igualada, Vilanova del Camí, Cuadra de Vilanova, Torre de Claramunt, Pobla de Claramunt y Capellades» ${ }^{41}$. Aunque las obras practicadas en el referido vial habían sido modestas, el letrado reconocía la necesidad de emprender otras de mayor envergadura que permitieran mejorar su trazado y solventar los inconvenientes que se reproducían de forma habitual en determinadas épocas del año.

Decidido a poner de manifiesto cuáles eran los puntos negros, dentro del término que comprendía la alcaldía mayor de Igualada, de la carretera que comunicaba Madrid con Barcelona, Buenaventura Claris realizó un croquis en el que, de oeste a este, iba marcando las zonas en las que cabía intervenir para facilitar las comunica-

38. A.G.S. Gracia y Justicia. Leg. 825. Informe de Mariano Berga y Felip. Tárrega, 2 de junio de 1784.

39. Nombrado alcalde mayor de Tárrega en el otoño de 1783, a comienzos del año siguiente obtenía la vara de Gerona. su ciudad de origen. Cfr. Gaceta de Madrid, 7 de octubre de 1783, p. 848; y A.G.S. Gracia y Justicia. Lib. 306.

40. Fueron empedradas unas ciento cincuenta varas en dicho camino.

41. A.G.S. Gracia y Justicia. Leg. 825. Informe de Buenaventura Claris y Postius. Igualada, 20 de marzo de 1784 . 
ciones. El referido vial empezaba en un mesón, situado a una media legua de Iguala$\mathrm{da}$, conocido como la Roxela; pues bien, desde este establecimiento hasta otro de las mismas características llamado de la Masa, el trazado era llano, pero desde este último hasta el molino Nuevo el terreno se volvía pantanoso. En las inmediaciones del referido molino había una pequeña bajada, al pie de la cual se unían dos pequeños arroyos cuyas avenidas en tiempo de aguaceros privaban el paso a los transeúntes. Para remediar dicho inconveniente Claris proponía la construcción de un puente con «un arco en cada arroyo», obra mediante la cual «quedarían disminuidas notablemente la dicha bajada y una subida que se sigue al entrar en el término de Igualada, inmediatamente después de pasados dichos arroyuelos».

La carretera continuaba por los arrabales y rambla de Igualada, donde su trazado era llano y bastante ancho, si bien no disponía de la pendiente necesaria para evitar la acumulación de lodos en épocas de lluvias, por lo que urgía una rápida intervención que solventase el problema ${ }^{42}$. Con las mismas características de 1lanura y anchura proseguía la calzada hasta alcanzar la riera de Odena, que servía de límite al término de Igualada con el de Vilanova del Camí.

En esa zona fronteriza se producía la unión de dicho torrente con el río Noya, el cual, tras mantener su curso de poniente a levante, al unirse con aquél giraba hacia el mediodía para seguir a partir de ese momento el curso de la riera de Odena. Un montecillo era el responsable del giro. Por el pie de la mencionada elevación discurría, asimismo, la carretera, la cual quedaba inundada e intransitable cada vez que las lluvias hacían subir el nivel de las aguas.

Según el alcalde mayor dos eran las posibles soluciones que cabía adoptar para solventar el problema anterior; el más efectivo, y también el más costoso, debido a la anchura del cauce, pasaba por la construcción de un puente en la riera de Odena ${ }^{+3}$; el segundo consistía en elevar un tanto el trazado de la carretera que discurría casi al ras del agua, «dirigiéndola con una subidita suave por el montecillo en cuyo pie se halla ${ }^{4+}$.

El siguiente obstáculo en el camino se presentaba al llegar al torrente Rigates donde, tanto la bajada y subida que se encontraba a su paso, como las detenciones de viajeros que causaban sus avenidas, podían tener fácil remedio de construirse un puente de un solo arco. Una vez superado el referido torrente se entraba en el término

42. Para solventar el problema Buenaventura Claris proponía que los dueños de lals casas de los arrabales y rambla empedrasen «el respectivo andar del frente de aquéllas, hasta vara y media o dos varas, y que el medio se cubriese con guijo o cascajos, aplicando en cada caso la pendiente necesaria para evitar la detención de las aguas, así como los atolladeros y cenagales tan frecuentes en épocas de lluvias. Para sufragar las mencionadas obras se recurriría al sobrante de propios de la villa de lgualada, de cuyos fondos se habían venido costeando hasta ese momento los tradicionales reparos roalizados en la zona.

43. Con la construcción de un puente para salvar el cauce del torrente de Odena se «escasarian la bajada del término de Igualada y la subida que se sigue en el de Vilanova del Camì.

44. Esta solución había sido propuesta a los vecinos de Vilanova del Camí en repetidas ocasiones a lo largo de 1783, pero éstos, acosados «de las enfermedades que padecían, cono y de lo costoso que le seria, se dejaron sobrecoger del desaliento en emprenderlo, consideríndolo por entonces mucho nás gravoso que las frecuentes precisas recomposiciones secuelas de las avenidas». 
de la Pobla de Claramunt, apareciendo nuevamente en el itinerario el río Noya; dejado éste atrás, el camino proseguía por terreno llano hasta el lugar de la Pobla, debiéndose vadear a continuación el enunciado río para, poco después, tropezar otra vez con el Noya, al que se le unía en ese tramo la riera Carme. Para vencer tantos inconvenientes el recurso a la construcción de puentes era rechazado en esta ocasión por el alcalde mayor, al entender que no era estrictamente necesaria, ya que:

«hacer puentes en estos tres pasos sería muchísima obra, que puede bien escusarse por lo ancho que tienen dichos pasos y poderse el rio en ellos fácilmente vadear sin peligro aun en sus avenidas, saltim (sic) a pocos ratos después de haber pasado el primer impetu de las mismas o luego que vayan menguando».

Superados los referidos obstáculos la carretera seguía subiendo lentamente por la Torre de Claramunt y Capellades o fuente de la Reina hasta tropezar de nuevo con el Noya en lo pas de l'aigua. Era éste un paso estrecho por el que discurrían unidas las aguas del Noya y Carme, juntando un caudal difícil de vadear en épocas normales e imposible en caso de crecidas:

«con las corrientes regulares siempre es paso malo, y con pocas avenidas intransitable».

Algunos restos de obras en el lecho del río informaban de la existencia antaño de un puente que permitía cruzarlo en dicho paso, puente que según Buenaventura Claris «fuera fácil construirlo con dos arcos medianos de piedra tosca, que abunda a las inmediaciones y se labra con facilidad, y labrada y puesta en los edificios se fortifica y endurece mucho, y se vuelve permanente y duradera, como lo acreditan los molinos de papel fabricados de dicha piedra en aquellas cercanías». Con la realización de la mencionada obra quedaría expedito el resto del camino, ya que desde el referido pas de l'aigua hasta Vallbona, donde concluía el partido de Igualada, la carretera discurría por zona llana y sin obstáculos.

Sólo un inconveniente encontraba el promotor del proyecto anterior para su realización: el desconocimiento de qué fondos emplear para sufragarlo. Aun así, Claris se aventuraba a proponer dos posibles soluciones: la primera pasaba por el recurso a los repartimientos, tanto entre los lugares del referido partido, como de los distritos vecinos que no tuviesen que contribuir a la realización de otras carreteras; la segunda solución consistía en la concesión de un tributo o derecho de pasaje por un determinado periodo de tiempo.

El mismo proyecto de construcción de carreteras que hemos visto promover a diferentes alcaldes mayores en otras tantas poblaciones fue también defendido por Pedro de Saravia, juez real ordinario del valle de Arán, quien glosó las ventajas de realizar un vial que mejorase las comunicaciones con Francia. Las duras condiciones meteorológicas que se repetían cada invierno, y que mantenían al valle incomunicado con el resto de Cataluña y Aragón, llevaron a Saravia a proponer la realización de un «camino carretero» desde Viella hasta San Beat, en Francia, villas separadas por unas siete leguas.

Las características del suelo, «naturalmente estéril, por ser todo él quebrado, montuoso, lleno de peñascos y cubierto de malezas», dificultaba el desarrollo de la agricultura en la zona, que quedaba reducida a «una escasísima cosecha de trigo y otros granos inferiores». Resultaba, por lo tanto, imprecindible recurrir a las importa- 
ciones de cereal ${ }^{45}$, así como de otros bienes de consumo, para el abastecimiento de la población.

Este recurso a productos venidos de fuera se complicaba sobremanera en la estación invernal, cuando las nieves cortaban cualquier tipo de comunicación con el resto del país; por esas fechas sólo la relación con Francia era factible, si bien la estrechez del paso, que únicamente permitía realizar el transporte a lomo de acémilas, propiciaba en ocasiones que las mulas, las cargas e incluso sus conductores se despeñasen, como de hecho había sucedido ya repetidas veces.

Para evitar semejantes accidentes, así como abaratar los costes de transporte ${ }^{40}$, Saravia proponía la construcción de una carretera por la cual pudiesen circular vehículos de ruedas. El coste de la misma, que el promotor de la idea estimaba en unos «doce a quince mil ducados de vellón», podría ser sufragado por los vecinos del valle en un intervalo de cuatro a seis años, o bien «sacarse del valor de algunos de los bosques que tiene cada población, atendido el número de ésta y las circunstancias que se presentasen al tiempo de la ejecución».

Aunque anteriormente hayamos citado de pasada un par de ejemplos, no queremos cerrar este apartado sin hacer una alusión directa, aunque breve, a otra de las empresas que debieron acometer los alcaldes mayores, ya por imposición, ya por propio interés: la repoblación forestal y la dotación arbórea de los paseos ${ }^{47}$.

En la visita que realizó en septiembre de 1782 al término de Igualada José Alonso Enríquez, juez de montes y plantíos de Tarragona, constató la aspereza, sequedad y mala calidad del terreno, por lo que no encontró en todo él sitio adecuado donde poder realizar un vivero de encinas; en su opinión, y la de los expertos que le acompañaban, sólo unos cuantos lugares resultaban adecuados para el repoblamiento arbóreo ${ }^{48}$, si bien limitado a dos únicas especies: álamos blancos y negros.

De la rapidez con que fueron atendidas las recomendaciones del citado juez visitador da buena cuenta el hecho de que a principios de 1784 ya se habían plantado a estaca 68 álamos.

En los restantes lugares en que tenía jurisdicción el alcalde mayor de Igualada también se prestaba especial atención a la repoblación forestal, esta vez por parte de sus propietarios directos. Según manifestó Buenaventura Claris, en dichos lugares, que «se componen de alquerías o casas de campo con separación y distancia unas de

45. Según informó Saravia, con el grano recolectado en el valle apenas podían cubrirse las necesidades de las dos terceras partes de sus habitantes.

46. Las cifras aportadas por Saravia permitían conocer que a lo largo de 1783 salieron «cerca de un millón de reales al reino de Francia para la compra de trigo, habiendo excedido el coste de su importación. según un prudente cálculo, de veinte mil pesetas, siendo así que en carros habría podido importarse con cuatro ó cinco mil, y ahorrarse el partido cerca de mil doblones en sólo este objeto». Vid. A.G.S. Gracia y Justicia. Leg. 525. Informe de Pedro Celestino Saravia. Viella, 16 de abril de 1784.

47. Un caso paradigmático del especial interés con que, en ocasiones, se abordó el tema es el de Francisco Javier Lozano, de cuya actuación en Albacete quedan sobradas huellas. Sobre el tema vid. IRLES VICENTE, M.C., «Albacete en el siglo XVIII: la institución corregimental y su componente humano», en Al-Basit n $\mathrm{n}^{\circ} \mathrm{l}$ ( (1998), pp. 98-99.

48. Según José Alonso Enríquez y su grupo de asesores sólo se consideraban adecuados para el plantío de árboles el arroyo de la villa de lgualada, así como las inmediaciones de un molino harinero. 
otras, conservan los dueños de ellas y aumentan sus respectivos bosquecitos, que en ellos reparan y consideran de mayor robustez, podándolos y criándolos para que crezcan y aumenten, y queden subrogados en lugar de los que acaso mueren o se cortan para leña por su conocida utilidad». Especial empeño había mostrado en la referida tarea Antonio Mariano de Padró y Vilosa, señor de Orps, en cuyo término había empezado a plantar «una considerable alameda de árboles de todas especies».

En una de las intervenciones que en este mismo sentido había llevado a cabo en la villa de Montblanch Nicolás María Esteban se plantaron ciento once álamos negros extramuros de la población, a fin de embellecer el principal paseo con que aquélla contaba; sin embargo, la sequedad de los tres meses siguientes provocaron la muerte de la mayoría de ellos.

$$
* * *
$$

Después de todo lo comentado, y a modo de conclusión, no nos resta sino apuntar que aunque fueran muchas las carencias existentes en las poblaciones catalanas de finales del Setecientos - tanto en la calidad del agua y su suministro, escaso desarrollo de la red de alcantarillado, o problemas de comunicación derivados de la práctica inexistencia de carreteras que permitiesen la circulación de vehículos-, el interés demostrado por los representantes del poder real posibilitó una incipiente mejora. Haría falta, no obstante, que transcurrieran muchos años, casi siglos, para que poblaciones de menor entidad política pudieran llegar a disfrutar de las ventajas que hemos visto introducir, en las postrimerías del siglo de las Luces, en los principales municipios catalanes. 